\title{
Management Approach to Thyroid Nodules
}

\section{Rodrigo Arrangoiz*, Fernando Cordera, David Caba, Eduardo Moreno, Enrique Luque de Leon, Manuel Muñoz}

Sociedad Quirúrgica S.C. at the American British Cowdray Medical Center, Mexico City, Mexico

Email: *rodrigo.arrangoiz@gmail.com

How to cite this paper: Arrangoiz, R., Cordera, F., Caba, D., Moreno, E., de Leon, E.L. and Muñoz, M. (2018) Management Approach to Thyroid Nodules. International Journal of Otolaryngology and Head \& Neck Surgery, 7, 214-227.

https://doi.org/10.4236/ijohns.2018.74023

Received: June 26, 2018

Accepted: July 27, 2018

Published: July 30, 2018

Copyright $\odot 2018$ by authors and Scientific Research Publishing Inc. This work is licensed under the Creative Commons Attribution International License (CC BY 4.0).

http://creativecommons.org/licenses/by/4.0/

\begin{abstract}
Thyroid nodules are a major health problem worldwide. The prevalence of palpable thyroid nodules in the general population is approximately $5 \%$ in women and $1 \%$ in men living in parts of the world with sufficient iodine. High resolution neck and thyroid ultrasound can detect thyroid nodules in a significant proportion of randomly selected individuals, with higher frequencies in women and the elderly population. The importance of thyroid nodules lies in the need to rule out cancer. The majority of thyroid nodules are benign, clinically irrelevant, and can be safely managed with a good surveillance program. The detection and diagnosis of differentiated thyroid cancer have evolved over the years with increased use of high resolution cervical and thyroid ultrasound, fine needle aspiration biopsy (FNAB), molecular testing, and thyroglobulin as a serum tumor marker. An algorithm that utilizes high resolution ultrasound and, when indicated, FNAB, and molecular testing for the diagnosis of thyroid nodules, facilitates a personalized, risk-based protocol that promotes high-quality care and minimizes cost and unnecessary testing. Our paper reviews the current, evidence-based management of newly diagnosed thyroid nodules.
\end{abstract}

\section{Keywords}

Thyroid Nodules, Thyroid Cancer, Thyroid FNA, Thyroid Nodule Workup

\section{Introduction}

Thyroid nodules are a major health problem worldwide. The prevalence of palpable thyroid nodules in the general population is approximately $5 \%$ in women and $1 \%$ in men living in parts of the world with sufficient iodine [1]. In contrast, high resolution neck and thyroid ultrasound can detect thyroid nodules 
in approximately $19 \%$ to $68 \%$ of randomly selected people, with higher frequencies in women and the elderly [2] [3]. The clinical importance of thyroid nodules lies in the need to rule out thyroid cancer, which occurs anywhere between $7 \%$ and $15 \%$ of cases, varying according to gender, age, history of exposure to radiation, family history, among other factors [4] [5].

The detection and diagnosis of differentiated thyroid cancer have evolved over the years with increased use of high resolution cervical and thyroid ultrasound, fine needle aspiration biopsy (FNAB), molecular testing, and thyroglobulin as a serum tumor marker. In this chapter, we will address the current evidence-based management of thyroid nodules.

\section{Definition of Thryoid Nodules}

A thyroid nodule is defined as a discrete lesion within the thyroid gland that is radiologically different from the surrounding thyroid parenchyma. Certain palpable lesions may not resemble a distinct radiologic abnormality [6]. Such abnormalities do not meet the stringent definition for a thyroid nodule. Nonpalpable nodules detected on ultrasound or by other imaging studies are termed incidentally discovered nodules or "incidentalomas" [7]. Nonpalpable nodules have the same risk of malignancy as do ultrasonographically confirmed palpable nodules of the same size [8]. Usually, only nodules greater than $1 \mathrm{~cm}$ in size should be evaluated since they have a greater potential to be clinically significant cancers [9]. Sporadically, there may be thyroid nodules less than $1 \mathrm{~cm}$ that require further evaluation because of clinical symptoms or associated lymphadenopathy [4] [9]. In very rare instances, some nodules less than $1 \mathrm{~cm}$ lack these ultrasonographic and clinical warning signs yet may nonetheless cause future morbidity and mortality.

\section{Initial Assessment of Thyroid Nodules}

Upon discovery of a thyroid nodule, a complete clinical history and a physical examination centered on the thyroid gland and adjacent regional lymph nodes should be performed. Relevant historical factors that predict malignancy in a thyroid nodule include a history of childhood radiation therapy to the head and neck region, total body radiation for bone marrow transplant, exposure to ionizing radiation in childhood or adolescence, familial thyroid carcinoma, or hereditary thyroid cancer syndrome (Cowden syndrome, familial polypoid adenomatosis, Carney complex, Werner syndrome, multiple endocrine neoplasia $2 \mathrm{~A}$, or multiple endocrine neoplasia $2 \mathrm{~B}$ ), a rapidly growing thyroid nodule and/or hoarseness [10] [11].

Relevant physical findings suggesting possible malignancy include vocal cord paralysis, cervical lymphadenopathy, and fixation of the thyroid nodule to surrounding tissues [12]. With the discovery of a thyroid nodule greater than $1 \mathrm{~cm}$ in any diameter, a serum thyroid stimulating hormone level (TSH) should be obtained (recommendation \# 2 of the American Thyroid Association [ATA]) 
[9]. If the TSH is low, a thyroid scan should be performed (this is the only indication nowadays to perform this study) to document whether the thyroid nodule is hyperfunctioning ("hot", tracer uptake is greater than the adjacent normal thyroid), iso-functioning ("warm", tracer uptake is equal to the surrounding normal thyroid), or non-functioning ("cold", tracer uptake is less than the adjacent normal thyroid tissue) [13]. Since hyperfunctioning thyroid nodules rarely contain malignancy, if one is found that corresponds to the nodule in question, a cytological evaluation is not necessary [9]. If there is obvious or subclinical hyperthyroidism, an additional evaluation with a thyroid scan is required [13]. High serum levels of TSH, even within high normal range, are associated with an increased risk of malignancy in the thyroid nodule, as well as a more advanced stage of the thyroid cancer [14].

Thyroglobulin $(\mathrm{Tg})$ has a very high specificity for thyroid tissue and has led to its evaluation as a disease marker for more than 30 years. Serum $\mathrm{Tg}$ concentrations were found to be increased in a range of thyroid disorders, most prominently in advanced thyroid carcinoma [15] [16]. Nevertheless, considerable overlap was found between levels observed in benign thyroid disorders and those observed in tumor patients. Furthermore, many patients with relatively small thyroid carcinomas had serum $\mathrm{Tg}$ concentrations that fell within the range of values found in healthy individuals [16]. Based on this evidence during the initial evaluation of thyroid nodules, it is not recommended to routinely obtain serum $\mathrm{Tg}$ (recommendation 3 of the ATA) [9]. As mentioned previously serum levels of Tg may be elevated in the vast majority of thyroid diseases (benign and malignant) and it is an insensitive and nonspecific test for the diagnosis of thyroid cancer [17] [18]. Even when the diagnosis of thyroid cancer is established standard preoperative measurement of serum $\mathrm{Tg}$ or anti-Tg antibodies is not recommended by the ATA (recommendation \# 34) [9]. Evidence from a systematic review and meta-analysis indicated that elevated preoperative levels of serum $\mathrm{Tg}$ may foresee a higher sensitivity for postoperative surveillance with serum Tg [19]. Anti-Tg antibodies obtained in the preoperative period do not appear to be an independent preoperative prognosticator of stage in patients with differentiated thyroid cancer (DTC), but the evidence is limited [19]. Evidence from the National Thyroid Cancer Treatment Cooperative Study (a large thyroid cancer registry that enrolled patients between 1987 and 2011), serum anti-Tg antibody status was not significantly associated with stage of disease on multivariate analysis, or with disease-free or overall survival on univariate or multivariate analyses [20]. Data that preoperative measurement of serum Tg impacts patient management or outcomes is not yet available.

The usefulness of serum calcitonin in the initial assessment of thyroid nodules has been evaluated in non-randomized prospective studies [21] [22] [23] [24], with mixed results, therefore, the ATA cannot recommend either for or against the routine measurement of serum calcitonin in patients with thyroid nodules (recommendation 4 of the ATA) [9]. 
A high-resolution ultrasound of the neck and thyroid should be performed in all patients with suspected thyroid nodules, nodular goiter, or any radiographic abnormality that suggests a thyroid nodule detected incidentally in another imaging study (computed tomography or magnetic resonance imaging, or 18 FDG-PET) (recommendation 6 of the ATA) [9]. The neck and thyroid ultrasound should evaluate the following characteristics [4] [9] [13]:

- The thyroid parenchyma:

- Homogeneous or heterogeneous

- The size of the thyroid gland

- The size, location, and ultrasonographic features of any thyroid nodule

- The presence or absence of suspicious cervical lymph nodes in the central or lateral compartments of the neck

The characteristics that should be evaluated on ultrasound are [25] [26]:

- Node size (in three dimensions)

- The location (example-right upper lobe/if it is anterior or posterior)

- Description of the ultrasonographic characteristics of the thyroid nodule:

- Composition of the nodule:

- Solid, cystic or spongiform

○ Echogenicity:

- Isoechoic, hyperechoic, hypoechoic

○ Margins:

- Regular

- Irregular: (defined as infiltrative, microlobulated or speculated)

- Presence and type of calcifications:

- Macro or microcalcifications

$\circ$ Shape:

- If the nodule is taller than wider

- Vascularity:

- Central or peripheral

The ultrasonographic pattern associated with a thyroid nodule confers a risk of malignancy, and combined with the size of the nodule, guides decision-making (Table 1). The ultrasonographic pattern of high suspicion of malignancy includes hypoechoic nodules, solid nodules, or nodules with mixed components (a solid and partially cystic hypoechoic nodule) with one or more of the following characteristics: irregular margins (infiltrative, microlobulated), microcalcifications, shape than wider, peripheral calcifications on the cyst wall, evidence of extra thyroid extension [27] [28] [29].

Fine needle aspiration biopsy (FNAB) is the most accurate and cost-effective way de evaluate suspicious thyroid nodules (recommendation \# 7 of the ATA) [9]. Thyroid nodules with a higher probability of obtaining a non-diagnostic cytology (cystic component greater than $25 \%$ to $50 \%$ ) or a sampling error (nodules difficult to palpate or located in the posterior portion of the thyroid lobe), it is preferred to perform a FNAB ultrasound guided [31] [32].

Figure 1, Figure 2 and Table 2 provide an algorithm for the initial assessment 
Table 1. Ultrasonographic patterns of thyroid nodules, estimated risk of malignancy, and management guidelines of thyroid nodules after FNAB [9] [30].

\begin{tabular}{|c|c|c|c|}
\hline $\begin{array}{l}\text { Ultrasonographic } \\
\text { Pattern }\end{array}$ & Ultrasonographic Characteristics & $\begin{array}{l}\text { Estimated Risk } \\
\text { of Malignancy }\end{array}$ & $\begin{array}{l}\text { FNA Size Cutoff } \\
\text { (largest dimension) }\end{array}$ \\
\hline High suspicion & $\begin{array}{l}\text { Solid hypoechoic nodule or solid hypoechoic component of a partially } \\
\text { cystic nodule with one or more of the following features: irregular } \\
\text { margins (infiltrative, microlobulated), microcalcifications, taller than } \\
\text { wide shape, rim calcifications with small extrusive soft tissue } \\
\text { component, evidence of extra thyroid extension (ETE) }\end{array}$ & $\begin{array}{l}\text { Greater than } 70 \% \\
-90 \%\end{array}$ & $\begin{array}{l}\text { FNA at equal or greater than } \\
1 \mathrm{~cm}\end{array}$ \\
\hline Intermediate suspicion & $\begin{array}{l}\text { Hypoechoic solid nodule with smooth margins without } \\
\text { microcalcifications, ETE, or taller than wide shape }\end{array}$ & $10 \%$ al $20 \%$ & $\begin{array}{l}\text { FNA at equal or greater than } \\
1 \mathrm{~cm}\end{array}$ \\
\hline Low suspicion & $\begin{array}{l}\text { Isoechoic or hyperechoic solid nodule, or partially cystic nodule with } \\
\text { eccentric solid areas, without microcalcification, irregular margin or } \\
\text { ETE, or taller than wide shape }\end{array}$ & $5 \%$ al $10 \%$ & $\begin{array}{l}\text { FNA at equal or greater than } \\
1.5 \mathrm{~cm}\end{array}$ \\
\hline Very low suspicion & $\begin{array}{l}\text { Spongiform or partially cystic nodules without any of the sonographic } \\
\text { features described in low, intermediate, or high suspicion patterns }\end{array}$ & Less than 3\% & $\begin{array}{l}\text { Consider FNA at equal or } \\
\text { greater } 2 \mathrm{~cm} \\
\text { Observation without FNA is } \\
\text { also an option }\end{array}$ \\
\hline Benign & Purely cystic nodules (no solid component) & Less than $1 \%$ & No biopsy \\
\hline
\end{tabular}

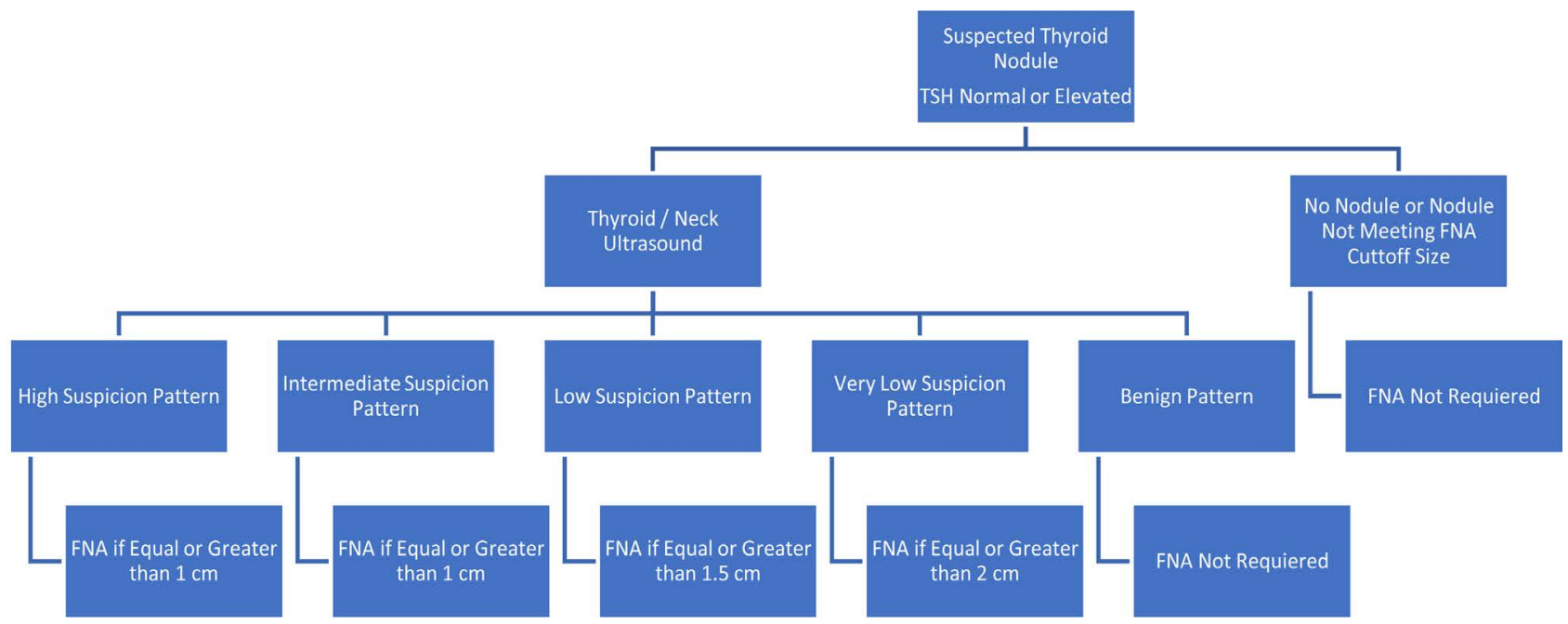

Figure 1. Algorithm for the initial evaluation and treatment of patients with thyroid nodules according to the ultrasound pattern.

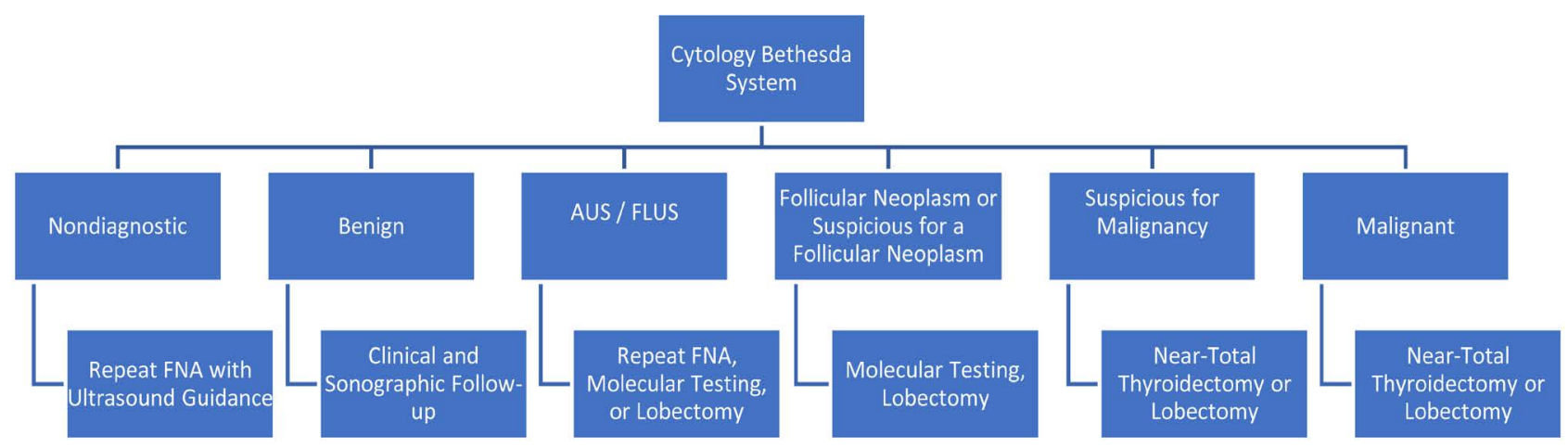

Figure 2. Algorithm for the treatment of patients with thyroid nodules according to the pattern the result of FNAB [30] [33]. 
Table 2. The 2017 Bethesda system for reporting thyroid Cytopathology [30].

\begin{tabular}{|c|c|c|c|}
\hline Diagnostic Category & $\begin{array}{l}\text { Risk of Malignancy } \\
\text { if NIFTP Not Cancer }\end{array}$ & $\begin{array}{l}\text { Risk of Malignancy } \\
\text { if NIFTP Equals Cancer }\end{array}$ & Usual Management \\
\hline Non-diagnostic or unsatisfactory & $5 \%$ to $10 \%$ & $5 \%$ to $10 \%$ & Repeat FNA with ultrasound guidance \\
\hline Benign & $0 \%$ to $3 \%$ & $0 \%$ to $3 \%$ & Clinical and sonographic follow-up \\
\hline $\begin{array}{l}\text { Atypia of undetermined significance or follicular } \\
\text { lesion of undetermined significance }\end{array}$ & $6 \%$ to $18 \%$ & $10 \%$ to $30 \%$ & Repeat FNA, molecular testing, or lobectomy \\
\hline $\begin{array}{l}\text { Follicular neoplasm or suspicious for a } \\
\text { follicular neoplasm }\end{array}$ & $10 \%$ to $40 \%$ & $25 \%$ to $40 \%$ & Molecular testing, or lobectomy \\
\hline Suspicious for malignancy & $45 \%$ to $60 \%$ & $50 \%$ to $75 \%$ & Near-total thyroidectomy or lobectomy \\
\hline Malignant & $94 \%$ to $96 \%$ & $97 \%$ to $99 \%$ & Near-total thyroidectomy or lobectomy \\
\hline
\end{tabular}

and management of patients with thyroid nodules based on their ultrasonographic pattern and the results of FNAB [9].

\section{The Bethesda System}

In the year 2007 the National Cancer Institute Thyroid FNA State of the Science Conference presented consensus recommendations known as the Bethesda System for Reporting Thyroid Cytopathology [34] [35]. The Bethesda system includes six diagnostic categories and offers an approximation of cancer risk within each category based upon literature review and expert opinion (Table 2) [30].

Current studies that utilized the criteria and terminology of the Bethesda system to a large series of patients have shown a good concordance in reporting FNA cytology, with $89 \%$ to $95 \%$ of samples being satisfactory for interpretation, $55 \%$ to $74 \%$ reported as definitively benign, and $2 \%$ to $5 \%$ as definitively malignant [36] [37] [38] [39]. The left-over samples are cytologically indeterminate, including atypia of undetermined significance or follicular lesion of undetermined significance (AUS/FLUS) in $2 \%$ to $18 \%$ of the thyroid nodules, follicular neoplasm or suspicious for follicular neoplasm (FN/SFN) in $2 \%$ to $25 \%$ of the thyroid nodules, and suspicious for malignancy in $1 \%$ to $6 \%$ of the thyroid nodules. The Bethesda system has proven highly beneficial, allowing physicinas to speak with the same terminology and better convey malignant risk.

\section{Non-Diagnostic or Unsatisfactory FNA Results}

Non-diagnostic or unsatisfactory FNAB are those that do not meet the established quantitative or qualitative requirements to say that the cytological assessment is adequate (the presence of at least six well-visualized groups of follicular cells, each group containing at least 10 well-preserved epithelial cells, preferably in a single slide) [30] [34] [40]. When FNA is performed in a thyroid nodule and the initial cytology result is non-diagnostic, FNAB should be repeated with the support of ultrasound guidance, and if available, cytological assessment should be performed at the time of FNAB (recommendation \# 10 of the ATA) [9] [41] 
[42] [43]. It has been suggested that FNAB should be repeated no earlier than three months after initial FNAB to avoid a falsely positive interpretation due to reactive changes induced by the biopsy [44]. Two recent studies have questioned the need for a three-month waiting period after the first FNAB because they found no correlation between the diagnostic/accuracy performance of the second FNAB and the waiting time between procedures [45] [46]. Thyroid nodules that have undergone multiple FNABs that turned out to be non-diagnostic without having an ultrasonographic pattern of high suspicion can undergo a period of observation vs. surgical excision to have a definitive histopathological diagnosis (recommendation 10 of the ATA) [9]. Surgical excision should be considered for histopathologic diagnosis if the cytologically non-diagnostic nodule has a high suspicion sonographic pattern, growth of the nodule (greater than $20 \%$ in two dimensions), is detected during US surveillance, or clinical risk factors for malignancy are present [9].

In several published series of patients classified according to the Bethesda system, non-diagnostic samples constituted $2 \%$ to $16 \%$ of all FNAB samples, of which $7 \%$ to $26 \%$ were resected [36] [37] [47]. The frequency of malignancy among all the FNAB initially classified as non-diagnostic was $2 \%$ to $4 \%$ and among the non-diagnostic samples that were finally resected the frequency of malignancy $9 \%$ to $32 \%$ [36] [37] [47].

\section{Benign Cytology}

If the thyroid nodule turns out to be benign in cytology after FNAB, no additional diagnostic or treatment studies are needed immediately (recommendation 11 of the ATA) [9]. Although prospective studies are lacking, the rates of malignancy in the retrospective series range from $1 \%$ to $2 \%$ [30] [33] [48] [49] [50].

\section{Atypia of Undetermined Significance (AUS) or Follicular Lesion of Undetermined Significance (FLUS) on Cytology}

Based on the Bethesda system, this diagnostic category is reserved for specimens that contain cells with architectural and/or nuclear atypia that are more prominent than expected for benign changes, but not sufficient to be placed in one of the highest-risk diagnostic categories [30] [33] [34] [51]. In the studies that used the criteria established by the Bethesda system, the risk of cancer for patients with AUS/FLUS who underwent surgery was $6 \%$ to $18 \%$ if NIFT (non-invasive follicular thyroid neoplasia with papillary nuclear characteristics) it is not considered cancer, and $10 \%$ to $30 \%$ if NIFT is considered a cancer [24].

For thyroid nodules with AUS/FLUS cytology after a FNAB, with clinical and ultrasonographic features of concern, the assessment can be continued by repeating the FNAB or if the technology is available, molecular tests can be used to complement the risk assessment of malignancy instead of preceding directly with a strategy of either surveillance or diagnostic surgery (lobectomy). Patient preference should be considered in decision-making (recommendation 15 of the 
ATA) [9]. If FNAB is not repeated, and molecular tests are not performed, or both studies were inconclusive, a diagnostic surgical excision may be performed for the thyroid nodules with Bethesda AUS/FLUS classification, according to the clinical risk factors, the ultrasonographic pattern, and patient preference (recommendation 15 of the ATA) [9].

\section{Folicular Neoplasm/Suspicious Folicular Neoplasm Cytology (FN/SFN)}

This diagnostic category of the Bethesda system is used for cellular aspirates:

- Composed by follicular cells arranged in an altered architectural pattern characterized by cell crowding and/or microfollicular formation, lacking nuclear characteristics of papillary carcinoma

or

- Composed almost exclusively oncocytic cells (Hurthle) [30] [33] [34] [52] [53].

This is a category has an intermediate risk of malignancy in the Bethesda system, with an estimated risk of malignancy between $10 \%$ amd $40 \%$ if NIFT is not considered cancer and between $25 \%$ to $40 \%$ if NIFT is considered cancer [9] [30]. This category represents $1 \%$ to $25 \%$ (average, 10\%) of all FNA samples [9].

Diagnostic surgical excision (lobectomy) is the long-established standard for the treatment of thyroid nodules with a FN/SFN cytology. However, if you have the technology, after taking into account the clinical assessment and the ultrasonographic characteristics, molecular tests can be used to complement the assessment of the risk of malignancy instead of proceeding directly with surgery (recommendation 16) of the ATA) [9]. Patient preference should be considered in clinical decision making. If the molecular tests cannot be performed or are indeterminate, surgical excision can be considered for the definitive diagnosis of thyroid nodules classified as FN/SFN (recommendation 16 of the ATA) [9].

\section{Suspicious Cytology for Malignancy}

This diagnostic category of the Bethesda system represents $1 \%$ to $6 \%$ of all FNABs and is reserved for aspirates with cytological features that generate a high suspicion of malignancy (mainly for papillary thyroid carcinoma) but that are not sufficient for a conclusive diagnosis [30] [33] [34] [54]. This is the highest risk category for indeterminate cytology in the Bethesda System, with an estimated cancer risk of $45 \%$ to $60 \%$ if NIFT is not considered cancer and $50 \%$ to $75 \%$ if NIFT is considered cancer [30]. Due to the high risk of cancer, the diagnosis of suspicious papillary carcinoma is an indication for surgery [9].

If FNAB results in a suspicious cytology for papillary thyroid carcinoma, the surgical treatment should be very similar to the management of a frankly malignant reported for the FNA. Factors that we must take into account in offering the definitive treatment with a suspicious cytology for papillary thyroid carcinoma, are the clinical risk factors, the ultrasonographic characteristics, the pa- 
tient's preference, and possibly the results of the molecular tests (BRAF, RAS, RET/PTC, PAX8/PPAR) (recommendation 17 of the ATA) [9].

\section{Malignant Cytology}

If the cytological result is diagnostic of primary thyroid malignancy, surgery is usually recommended (recommendation 12 of the ATA) [9].

A cytology diagnosis of primary thyroid malignancy will almost always lead to thyroid surgery. However, in some parts of the world under research protocol active surveillance can be offered as an alternative to immediate surgery in certain patients who meet some very specific criteria [45] [46]:

- Patients with very low risk tumors (papillary microcarcinomas without clinically evident metastases or local invasion, and without convincing cytological evidence of aggressive disease)

- Patients with high surgical risk due to multiple comorbidities

- Patients with a relatively short lifespan (severe cardiopulmonary disease, other malignancies, very old age)

- Patients with concurrent medical or surgical problems that must be addressed before thyroid surgery

\section{Molecular Studies in the Assessment of Thyroid Nodules}

The principal proposed of molecular markers in indeterminate thyroid FNA specimens is diagnostic (ruling out or ruling in malignancy), with the connotation of a companion use to inform decision-making on primary surgical treatment (i.e., the decision to perform surgery and if so, the extent of surgery) [9].

Several studies on the use of molecular tests in patients with indeterminate FNA cytology respectively evaluated a panel of seven genes for genetic mutations and chromosomal rearrangement (BRAF, RAS, RET/PTC, PAX8/PPAR) [55], an expression gene classifier (GEC 167; expression of the messenger RNA of 167 genes) [56], and immunohistochemistry of galectin-3 (in cell blocks) [57]. An ideal "rule-in" test would have a positive predictive value (PPV) for histopathologically proven malignancy similar to a malignant cytologic diagnosis (98.6\%), and an ideal "rule-out" test would have a negative predictive value (NPV) similar to a benign cytologic diagnosis (96.3\%) (predictive value estimates are based on a meta-analysis of performance of the Bethesda system) [38], and these would hold true with a reasonable degree of precision and reproducibility. Currently, there is no single optimal molecular test that can definitively confirm or rule out a malignancy in all cases of indeterminate cytology, and more studies are needed in the long term to demonstrate clinical utility before it becomes the standard but the future of the evaluation of thyroid nodules and the management is going in this direction.

\section{Conclusion}

Thyroid nodules are very common, being detected in up to $65 \%$ of the general 
population with a lifetime risk for developing a palpable thyroid nodule been anywhere between $5 \%$ and $10 \%$, however, high resolution ultrasound has revealed thyroid nodules in $19 \%$ to $68 \%$ of randomly selected individuals. The vast majority of thyroid nodules is benign, clinically irrelevant, and can be safely managed with a good surveillance program. The main objective of the initial evaluation and long-term management of thyroid nodules is the identification of the thyroid nodules that harbor a clinically significant cancer, cause symptoms, or may progress leading eventually to a surgical solution. A process that utilizes high resolution neck and thyroid ultrasound, when indicated FNA, and molecular testing, allows a personalized, risk-based approach that encourages high-quality care and minimizes cost and needless testing.

\section{Conflicts of Interest}

The authors declare no conflicts of interest regarding the publication of this paper.

\section{References}

[1] Vander, J.B., Gaston, E.A. and Dawber, T.R. (1968) The Significance of Nontoxic Thyroid Nodules. Final Report of a 15-Year Study of the Incidence of Thyroid Malignancy. Annals of Internal Medicine, 69, 537-540. https://doi.org/10.7326/0003-4819-69-3-537

[2] Tan, G.H. and Gharib, H. (1997) Thyroid Incidentalomas: Management Approaches to Nonpalpable Nodules Discovered Incidentally on Thyroid Imaging. Annals of Internal Medicine, 126, 226-231. https://doi.org/10.7326/0003-4819-126-3-199702010-00009

[3] Guth, S., et al. (2009) Very High Prevalence of Thyroid Nodules Detected by High Frequency (13 MHz) Ultrasound Examination. European Journal of Clinical Investigation, 39, 699-706. https://doi.org/10.1111/j.1365-2362.2009.02162.x

[4] Hegedus, L. (2004) Clinical Practice. The thyroid Nodule. The New England Journal of Medicine, 351, 1764-1771. https://doi.org/10.1056/NEJMcp031436

[5] Mandel, S.J. (2004) A 64-Year-Old Woman with a Thyroid Nodule. JAMA, 292, 2632-2342. https://doi.org/10.1001/jama.292.21.2632

[6] Marqusee, E., et al. (2000) Usefulness of Ultrasonography in the Management of Nodular Thyroid Disease. Annals of Internal Medicine, 133, 696-700. https://doi.org/10.7326/0003-4819-133-9-200011070-00011

[7] Russ, G., et al. (2014) Thyroid Incidentalomas: Epidemiology, Risk Stratification with Ultrasound and Workup. European Thyroid Journal, 3, 154-163. https://doi.org/10.1159/000365289

[8] Hagag, P., Strauss, S. and Weiss, M. (1998) Role of Ultrasound-Guided Fine-Needle Aspiration Biopsy in Evaluation of Nonpalpable Thyroid Nodules. Thyroid, 8, 989-995. https://doi.org/10.1089/thy.1998.8.989

[9] Haugen, B.R., et al. (2016) 2015 American Thyroid Association Management Guidelines for Adult Patients with Thyroid Nodules and Differentiated Thyroid Cancer: The American Thyroid Association Guidelines Task Force on Thyroid Nodules and Differentiated Thyroid Cancer. Thyroid, 26, 1-133.

https://doi.org/10.1089/thy.2015.0020 
[10] Curtis, R.E., et al. (1997) Solid Cancers after Bone Marrow Transplantation. The New England Journal of Medicine, 336, 897-904. https://doi.org/10.1056/NEJM199703273361301

[11] Pacini, F., et al. (1997) Post-Chernobyl Thyroid Carcinoma in Belarus Children and Adolescents: Comparison with Naturally Occurring Thyroid Carcinoma in Italy and France. The Journal of Clinical Endocrinology and Metabolism, 82, 3563-3569. https://doi.org/10.1210/jc.82.11.3563

[12] Thomas, R.M., Nancy, M.A.H., Perrier, D. and Grubbs, E.G. (2012) Well Differentiated Carcinoma of the Thyroid and Neoplasms of the Parathyroid Glands. Fourth Edition. In: Anderson, M.D., Ed., Surgical Oncology Handbook: Fifth Edition, Vol. 1, Lippincott Williams and Wilkins, Philadelphia, 900.

[13] Gharib, H. and Papini, E. (2007) Thyroid Nodules: Clinical Importance, Assessment, and Treatment. Endocrinology and Metabolism Clinics of North America, 36, 707-735. https://doi.org/10.1016/j.ecl.2007.04.009

[14] Haymart, M.R., et al. (2008) Higher Serum Thyroid Stimulating Hormone Level in Thyroid Nodule Patients Is Associated with Greater Risks of Differentiated Thyroid Cancer and Advanced Tumor Stage. The Journal of Clinical Endocrinology \& $\mathrm{Me}$ tabolism, 93, 809-814. https://doi.org/10.1210/jc.2007-2215

[15] Herle, A.J. and Uller, R.P. (1975) Elevated Serum Thyroglobulin. A Marker of Metastases in Differentiated Thyroid Carcinomas. The Journal of Clinical Investigation, 56, 272-277. https://doi.org/10.1172/JCI108090

[16] Gerfo, P.L., et al. (1979) Thyroglobulin in Benign and Malignant Thyroid Disease. JAMA, 241, 923-924. https://doi.org/10.1001/jama.1979.03290350043022

[17] Lee, E.K., et al. (2012) Preoperative Serum Thyroglobulin as a Useful Predictive Marker to Differentiate Follicular Thyroid Cancer from Benign Nodules in Indeterminate Nodules. Journal of Korean Medical Science, 27, 1014-1018. https://doi.org/10.3346/jkms.2012.27.9.1014

[18] Suh, I., et al. (2010) Serum Thyroglobulin Is a Poor Diagnostic Biomarker of Malignancy in Follicular and Hurthle-Cell Neoplasms of the Thyroid. The American Journal of Surgery, 200, 41-46. https://doi.org/10.1016/j.amjsurg.2009.08.030

[19] Spencer, C.A., et al. (2005) Clinical Impact of Thyroglobulin (Tg) and Tg Autoantibody Method Differences on the Management of Patients with Differentiated Thyroid Carcinomas. The Journal of Clinical Endocrinology \& Metabolism, 90, 5566-5575. https://doi.org/10.1210/jc.2005-0671

[20] McLeod, D.S., et al. (2014) Prognosis of Differentiated Thyroid Cancer in Relation to Serum Thyrotropin and Thyroglobulin Antibody Status at Time of Diagnosis. Thyroid, 24, 35-42. https://doi.org/10.1089/thy.2013.0062

[21] Elisei, R., et al. (2004) Impact of Routine Measurement of Serum Calcitonin on the Diagnosis and Outcome of Medullary Thyroid Cancer: Experience in 10,864 Patients with Nodular Thyroid Disorders. The Journal of Clinical Endocrinology \& Metabolism, 89, 163-168. https://doi.org/10.1210/jc.2003-030550

[22] Hahm, J.R., et al. (2001) Routine Measurement of Serum Calcitonin Is Useful for Early Detection of Medullary Thyroid Carcinoma in Patients with Nodular Thyroid Diseases. Thyroid, 11, 73-80. https://doi.org/10.1089/10507250150500694

[23] Niccoli, P., et al. (1997) Interest of Routine Measurement of Serum Calcitonin: Study in a Large Series of Thyroidectomized Patients. The French Medullary Study Group. The Journal of Clinical Endocrinology \& Metabolism, 82, 338-341. https://doi.org/10.1210/jcem.82.2.3737 
[24] Costante, G., et al. (2007) Predictive Value of Serum Calcitonin Levels for Preoperative Diagnosis of Medullary Thyroid Carcinoma in a Cohort of 5817 Consecutive Patients with Thyroid Nodules. The Journal of Clinical Endocrinology \& Metabolism, 92, 450-455. https://doi.org/10.1210/jc.2006-1590

[25] Smith-Bindman, R., et al. (2013) Risk of Thyroid Cancer Based on Thyroid Ultrasound Imaging Characteristics: Results of a Population-Based Study. JAMA Internal Medicine, 173, 1788-1796. https://doi.org/10.1001/jamainternmed.2013.9245

[26] Brito, J.P., et al. (2014) The Accuracy of Thyroid Nodule Ultrasound to Predict Thyroid Cancer: Systematic Review and Meta-Analysis. The Journal of Clinical Endocrinology \& Metabolism, 99, 1253-1263. https://doi.org/10.1210/jc.2013-2928

[27] Horvath, E., et al. (2009) An Ultrasonogram Reporting System for Thyroid Nodules Stratifying Cancer Risk for Clinical Management. The Journal of Clinical Endocrinology \& Metabolism, 94, 1748-1751. https://doi.org/10.1210/jc.2008-1724

[28] Tae, H.J., et al. (2007) Diagnostic Value of Ultrasonography to Distinguish between Benign and Malignant Lesions in the Management of Thyroid Nodules. Thyroid, 17, 461-466. https://doi.org/10.1089/thy.2006.0337

[29] Ito, Y., et al. (2007) Ultrasonographic Evaluation of Thyroid Nodules in $900 \mathrm{~Pa}$ tients: Comparison among Ultrasonographic, Cytological, and Histological Findings. Thyroid, 17, 1269-1276. https://doi.org/10.1089/thy.2007.0014

[30] Cibas, E.S. and Ali, S.Z. (2017) The 2017 Bethesda System for Reporting Thyroid Cytopathology. Thyroid, 27, 1341-1346. https://doi.org/10.1089/thy.2017.0500

[31] Alexander, E.K., et al. (2002) Assessment of Nondiagnostic Ultrasound-Guided Fine Needle Aspirations of Thyroid Nodules. The Journal of Clinical Endocrinology \& Metabolism, 87, 4924-4927. https://doi.org/10.1210/jc.2002-020865

[32] Danese, D., et al. (1998) Diagnostic Accuracy of Conventional versus Sonography-Guided Fine-Needle Aspiration Biopsy of Thyroid Nodules. Thyroid, 8, 15-21. https://doi.org/10.1089/thy.1998.8.15

[33] Cibas, E.S. and Ali, S.Z. (2009) The Bethesda System for Reporting Thyroid Cytopathology. Thyroid, 19, 1159-1165. https://doi.org/10.1089/thy.2009.0274

[34] Baloch, Z.W., et al. (2008) Diagnostic Terminology and Morphologic Criteria for Cytologic Diagnosis of Thyroid Lesions: A Synopsis of the National Cancer Institute Thyroid Fine-Needle Aspiration State of the Science Conference. Diagnostic Cytopathology, 36, 425-437. https://doi.org/10.1002/dc.20830

[35] Crippa, S., et al. (2010) The Bethesda System for Reporting Thyroid Fine-Needle Aspiration Specimens. American Journal of Clinical Pathology, 134, 343-344. https://doi.org/10.1309/AJCPXM9WIRQ8JZBJ

[36] Theoharis, C.G., et al. (2009) The Bethesda Thyroid Fine-Needle Aspiration Classification System: Year 1 at an Academic Institution. Thyroid, 19, 1215-1223. https://doi.org/10.1089/thy.2009.0155

[37] Luu, M.H., et al. (2011) Improved Preoperative Definitive Diagnosis of Papillary Thyroid Carcinoma in FNAs Prepared with Both ThinPrep and Conventional Smears Compared with FNAs Prepared with ThinPrep Alone. Cancer Cytopathology, 119, 68-73. https://doi.org/10.1002/cncy.20124

[38] Bongiovanni, M., et al. (2012) The Bethesda System for Reporting Thyroid Cytopathology: A Meta-Analysis. Acta Cytologica, 56, 333-339. https://doi.org/10.1159/000339959

[39] Nayar, R. and Ivanovic, M. (2009) The Indeterminate Thyroid Fine-Needle Aspiration: Experience from an Academic Center Using Terminology Similar to That 
Proposed in the 2007 National Cancer Institute Thyroid Fine Needle Aspiration State of the Science Conference. Cancer, 117, 195-202.

https://doi.org/10.1002/cncy.20029

[40] Crothers, B.A., Henry, M.R., Firat, P., Frates, M.C. and Rossi, E.D. (2010) Nondiagnostic/Unsatisfactory. In: Ali, S.Z. and Cibas, E.S., Eds., The Bethesda System for Reporting Thyroid Cytopathology: Definitions, Criteria, and Explanatory Notes, Springer, Berlin, 7-18.

[41] Baloch, Z.W., et al. (2000) Ultrasound-Guided Fine-Needle Aspiration Biopsy of the Thyroid: Role of On-Site Assessment and Multiple Cytologic Preparations. Diagnostic Cytopathology, 23, 425-429. https://doi.org/10.1002/1097-0339(200012)23:6<425::AID-DC14>3.0.CO;2-3

[42] Braga, M., et al. (2001) Efficacy of Ultrasound-Guided Fine-Needle Aspiration Biopsy in the Diagnosis of Complex Thyroid Nodules. The Journal of Clinical Endocrinology \& Metabolism, 86, 4089-4091. https://doi.org/10.1210/jcem.86.9.7824

[43] Wu, H.H., Rose, C. and Elsheikh, T.M. (2012) The Bethesda System for Reporting Thyroid Cytopathology: An Experience of 1,382 Cases in a Community Practice Setting with the Implication for Risk of Neoplasm and Risk of Malignancy. Diagnostic Cytopathology, 40, 399-403. https://doi.org/10.1002/dc.21754

[44] Layfield, L.J., et al. (2008) Post-Thyroid FNA Testing and Treatment Options: A Synopsis of the National Cancer Institute Thyroid Fine Needle Aspiration State of the Science Conference. Diagnostic Cytopathology, 36, 442-448.

https://doi.org/10.1002/dc.20832

[45] Singh, R.S. and Wang, H.H. (2011) Timing of Repeat Thyroid Fine-Needle Aspiration in the Management of Thyroid Nodules. Acta Cytologica, 55, 544-548. https://doi.org/10.1159/000334214

[46] Lubitz, C.C., et al. (2012) Diagnostic Yield of Nondiagnostic Thyroid Nodules Is Not Altered by Timing of Repeat Biopsy. Thyroid, 22, 590-594.

https://doi.org/10.1089/thy.2011.0442

[47] Ahmed, M., et al. (2011) Analysis of the Efficacy and Toxicity of Sorafenib in Thyroid Cancer: A Phase II Study in a UK Based Population. European Journal of Endocrinology, 165, 315-322. https://doi.org/10.1530/EJE-11-0129

[48] Orlandi, A., et al. (2005) Repeated Fine-Needle Aspiration of the Thyroid in Benign Nodular Thyroid Disease: Critical Evaluation of Long-Term Follow-Up. Thyroid, 15, 274-278. https://doi.org/10.1089/thy.2005.15.274

[49] Chehade, J.M., et al. (2001) Role of Repeated Fine-Needle Aspiration of Thyroid Nodules with Benign Cytologic Features. Endocrine Practice, 7, 237-243. https://doi.org/10.4158/EP.7.4.237

[50] Oertel, Y.C., et al. (2007) Value of Repeated Fine Needle Aspirations of the Thyroid: An Analysis of over Ten Thousand FNAs. Thyroid, 17, 1061-1066. https://doi.org/10.1089/thy.2007.0159

[51] Krane, J.F., VanderLaan, P.A., Faquin, W.C. and Renshaw, A.A. (2012) The Atypia of Undetermined Significance/Follicular Lesion of Undetermined Significance. Malignant Ratio: A Proposed Performance Measure for Reporting in the Bethesda System for Thyroid Cytopathology. Cancer Cytopathology, 120, 111-116.

[52] Faquin, W.C., Michael, C.W., Renshaw, A.A. and Vielh, P. (2010) Follicular Neoplasm, Hürthle Cell (Oncocytic) Type/Suspicious for a Follicular Neoplasm, Hürthle Cell (Oncocytic) Type. In: Ali, S.Z. and Cibas, E.S., Eds., The Bethesda System for Reporting Thyroid Cytopathology: Definitions, Criteria, and Explanatory Notes, Springer, Berlin, 81-100. 
[53] Henry, M.R., DeMay, R.M. and Follicular, B.K. (2010) Neoplasm/Suspicious for a Follicular Neoplasm. In: Ali, S. and Cibas, E.S., Eds., The Bethesda System for Reporting Thyroid Cytopathology: Definitions, Criteria and Explanatory Notes, Springer, Berlin, 51-58.

[54] Wang, H.H. and Clark, D.P. (2010) Suspicious for Malignancy. In: Ali, S.Z. and Cibas, E.S., Eds., The Bethesda System for Reporting Thyroid Cytopathology, Springer Science+Business Medica, Berlin.

[55] Nikiforov, Y.E., et al. (2011) Impact of Mutational Testing on the Diagnosis and Management of Patients with Cytologically Indeterminate Thyroid Nodules: A Prospective Analysis of 1056 FNA Samples. The Journal of Clinical Endocrinology \& Metabolism, 96, 3390-3397. https://doi.org/10.1210/jc.2011-1469

[56] Alexander, E.K., et al. (2012) Preoperative Diagnosis of Benign Thyroid Nodules with Indeterminate Cytology. The New England Journal of Medicine, 367, 705-715. https://doi.org/10.1056/NEJMoa1203208

[57] Bartolazzi, A., et al. (2008) Galectin-3-Expression Analysis in the Surgical Selection of Follicular Thyroid Nodules with Indeterminate Fine-Needle Aspiration Cytology: A Prospective Multicentre Study. The Lancet Oncology, 9, 543-549. https://doi.org/10.1016/S1470-2045(08)70132-3 